\title{
Unique expression of HLA-DR (la-like) antigen in the lesions of polar tuberculoid leprosy
}

\author{
MARIAN J RIDLEY \& D S RIDLEY \\ Hospital for Tropical Diseases, London NW1 OPE
}

Received for publication 11 January 1982

\begin{abstract}
Summary HLA-DR antigen was demonstrated in the skin lesions in leprosy in 11 out of 11 polar tuberculoid (TT) cases, in 3 of 6 near-tuberculoid cases in reaction and in 0 out of 38 other cases covering the spectrum from BT to LL. This antigen is therefore a good marker for the TT group. It is suggested that genetic markers may be associated with the rare TT group alone because, among those susceptible to leprosy, they denote the strong immune response that is needed to sustain this position in the spectrum. Susceptibility has not been explained.
\end{abstract}

\section{Introduction}

Leprosy presents a continuous clinical and histological spectrum ${ }^{1}$ which correlates with a continuous gradation of lymphocyte performance. ${ }^{2}$ However, a recent study of skin biopsies across the spectrum using the immunoperoxidase technique demonstrated important features which were not continuous. ${ }^{3}$ Immunoglobulins, complement and some inflammatory mediators were found to correlate with the bacterial load over almost the whole spectrum, but there was paradoxically a peak at the tuberculoid (TT) pole where bacilli are most scanty. This raised the possibility that the rare TT group might be the only group which did not share the immunological defect of lepromatous leprosy.

These conclusions call to mind the results of genetic studies in leprosy. There is a preferential inheritance of the HLA and HLA-DR 2 marker by patients with tuberculoid (mainly TT) leprosy, ${ }^{4,5}$ though the association has been observed only in families. It was less strong (not significant) in a mainly BT group of patients, ${ }^{6}$ and there are no known genetic markers associated either with lepromatous leprosy or with leprosy patients as a whole. ${ }^{4,5,7}$ These results have been interpreted as supporting the hypothesis of an autosomal recessive trait coding for susceptibility to tuberculoid leprosy which is linked with HLA. ${ }^{5}$ Susceptibility to lepromatous leprosy is less likely to be due to a single gene than to multiple factors, genetic or otherwise. ${ }^{7}$ 
In the present paper we reconsider this genetic hypothesis in the light of an immunoperoxidase study across the spectrum of leprosy, using an anti-human HLA-DR antibody raised in the mouse. The antigen thereby detected is HLA$\mathrm{DR}$, which is considered to be the human equivalent of the rodent Ia antigen.

\section{Patients and methods}

Fifty-two patients with leprosy were studied: $11 \mathrm{TT}, 8 \mathrm{BT}, 5 \mathrm{BB}, 5 \mathrm{BL}$ and $10 \mathrm{LL}$; in addition a number of patients undergoing immunological reactions involving an increase of hypersensitivity were included; this resulted in upgrading from BT to TT in 6, and from BL to BT in 4. Three other patients were downgrading from $\mathrm{BT}$ towards $\mathrm{BB}$. Biopsies of skin lesions were fixed in a formalin-mercuric chloride-acetic acid mixture, embedded in paraffin wax, and sections were processed by the immunoperoxidase technique.

The indirect peroxidase method was used. Ia antibody (supernatant) was diluted $1 / 4$ in Tris buffer for optimal demonstration as determined by positive staining of Langerhans cells. The sites of binding of the antibody were revealed by peroxidase conjugated rabbit anti-mouse Ig (Mercia-Brocades) diluted 1/20 with Tris buffer plus $0.03 \mathrm{ml} / 10 \mathrm{ml}$ of normal human serum diluted $1 / 25$ with Tris, in order to block any reactivity against human immunoglobulin.

\section{Results}

All 11 lesions of TT leprosy and 3 of the $6 \mathrm{BT}$ reactions resulting in enhanced immunological status (BT-TT) had positive HLA-DR staining cells. The cells were of dendritic appearance and were seen in the dense lymphocytic cuff around the epithelioid cell mass of the granuloma. Langhans giant cells at the periphery of the granuloma were also positive. The material was finely granular and located mainly at the boundary of the cell. None of the other 38 lesions ranging from BT to LL contained positively stained cells. Thus, apart from some near-tuberculoid cases in reaction, Ia-like antigen was unique to the TT group.

\section{Discussion}

We do not suggest that the HLA-DR antigen demonstrated here represents the whole of the HLA-DR antigen present in leprosy lesions. Ia antigen is present on surface membranes, though in skin the detected antigen may be intracytoplasmic. ${ }^{8}$ The immunoperoxidase technique is adapted mainly for the detection of intracytoplasmic factors. The results demonstrate an antigen which may 
represent either intracytoplasmic synthesis or specific localization within cells. Recognition by primed T cells of soluble or disintegrated antigens, as in a TT granuloma, depends on binding or processing by a subpopulation of Ia positive cells. ${ }^{9}$ Our results suggest that this sub-population is included amongst cells identified by the immunoperoxidase technique.

The genetic constitution of our patients is not known, but the linkage of HLA-DR antigen with the granuloma of the strictly defined TT component ${ }^{10}$ of the broader tuberculoid group was clear cut. This could be interpreted in more than one way. If the Ia phenotype is regarded as the expression of an immune response gene it would imply that this gene, under the conditions of our study, constitutes a reliable marker for the extreme polar tuberculoid group while it is absent from the remainder of the patients who contract leprosy. On the other hand our series of HLA-DR positive TT patients included a small group that had upgraded from BT as a result of a severe reaction reflecting an increase of delayed hypersensitivity. If patients can on occasion acquire Ia-like (HLA-DR) antigen, they can presumably also on other occasions lose it. This alternative is the more likely in the light of experimental evidence that Ia is labile, and depends on the stimulus. ${ }^{8,11}$

It would appear that immunoperoxidase HLA-DR antigen might be a useful marker for classification, and in connection with future genetic studies. Its relationship to the genetic make-up of leprosy patients needs to be elucidated, but the present results suggest that the association of tuberculoid leprosy with HLA-DR2 might indicate only that a strong immune response is necessary to sustain the polar tuberculoid group. Patients who are susceptible to leprosy would develop the TT form if they have good immune response genes, the nontuberculoid form if they do not. This would be consistent both with the genetic findings, and with the strong production of immunological factors in TT despite the low bacterial load. ${ }^{3}$

On this view the nature of the susceptibility to leprosy in a minority of the human race remains to be unravelled. Perhaps one should be looking for genes not primarily involved in the immune response, or for shared antigens which would impair the host's recognition of the leprosy bacillus as a foreign agent.

\section{Acknowledgement}

We are grateful to Dr D Y Mason (Oxford) for the supply of Ia-like antiserum and for useful comments, and to Miss Susan Langeveld for valuable technical assistance.

\section{References}

1 Ridley DS, Jopling WH. Classification of leprosy according to immunity. Int J Lepr, 1966; 34: 255-73. 


\section{2}

Marian J Ridley and D S Ridley

${ }^{2}$ Myrvang B, Godal T, Ridley DS, Fröland SS, Song YK. Immune responsiveness to Mycobacterium leprae and other mycobacterial antigens throughout the clinical and histopathological spectrum of leprosy. Clin exp Immunol, 1973; 14: 541-53.

3 Ridley MJ, Russell DF, Ridley DS. An immunoperoxidase study of immunological factors in skin lesions across the spectrum of leprosy. Int J Lepr, 1982; 50: 11-17.

${ }^{4}$ Eden W van, van Rood JJ. Genetic regulation of immune responsiveness in man. In: Immunological Aspects of Leprosy, Tuberculosis and Leishmaniasis. ed. DP Humber. International Congress Series. Excerpta Medica, 1981;201-213.

${ }^{5}$ Eden W van, Vries RRP de, Mehra NK, Vaidya MC, Amaro JD', Rood JJ van. HLA segregation of tuberculoid leprosy: confirmation of the $\mathrm{DR}_{2}$ marker. J Inf Dis, 1980; 141 : 693-701.

6 Rea TH, Terasaki PI. HLA-DR antigens in tuberculoid and lepromatous leprosy. Lepr Rev, 1980; 51: 117-23.

7 Smith DG. The genetic marker hypothesis for susceptibility to lepromatous leprosy. Hum Genet, 1979; 50: 163-77.

${ }^{8}$ Mason DW, Dallman M, Barclay AN. Graft-versus-host disease induces expression of Ia an tigen in rat epidermal cells and gut epithelium. Nature, 1981;293: 150-51.

9 Abramson SL, Puck JM, Rich RR. Antigen presentation to human T lymphocytes. 1. Different requirements for stimulation by hapten-modified cells vs cell sonicates. J Exp Med, 1981; 154: 1005-15.

10 Ridley DS. The pathogenesis and classification of the polar tuberculoid group. Lepr Rev, 1982; 53: 19-26.

11 Beller DI, Kiely J-M, Unanue ER. Regulation of macrophage populations. I. Preferential induction of Ia rich peritoneal exudates by immunologic stimuli. $J$ Immunol, 1980; 124: $1426-32$. 